\title{
Seeing Is Believing: Headway27 as a Highly Visible and Versatile Microcatheter with Ideal Dimensions for Stroke Thrombectomy
}

\author{
William J. Ares ${ }^{a, b}$ Benjamin M. Zussman ${ }^{a, b}$ Cynthia L. Kenmuir ${ }^{a, c}$ \\ Gregory M. Weiner ${ }^{a, b}$ Habibullah Ziayee ${ }^{a, c}$ Devin Burke ${ }^{a, c}$ \\ Ashutosh P. Jadhav a, c Tudor G. Jovin ${ }^{a, c}$ Brian T. Jankowitz ${ }^{a, b}$ \\ Bradley A. Gross ${ }^{a, b}$ \\ a Stroke Institute, University of Pittsburgh Medical Center, Pittsburgh, PA, USA; \\ ${ }^{b}$ Department of Neurological Surgery, University of Pittsburgh Medical Center, \\ Pittsburgh, PA, USA; ' Department of Neurology, University of Pittsburgh Medical Center, \\ Pittsburgh, PA, USA
}

\section{Keywords}

Stroke $\cdot$ Thrombectomy $\cdot$ Technique $\cdot$ Catheter

\begin{abstract}
Introduction: Microcatheter selection is an infrequent focus of stroke thrombectomy technique evaluation. The Headway 27 microcatheter strikes an excellent balance of microcatheter dimensions ( $156 \mathrm{~cm}$ length, $2.6 \mathrm{Fr}$ distal OD, ID 0.027 inches) and visibility, making it ideal for stroke thrombectomy. Methods: We evaluated a prospectively maintained acute stroke thrombectomy database containing 50 consecutive cases using the Headway 27 microcatheter. From the database, patient demographics, clinical and angiographic information as well as procedural technical details and complications were extracted. Results: Manual aspiration thrombectomy (MAT) was performed alone in $72 \%$ of cases, stentriever-assisted MAT was performed in $6 \%$ of cases, and a combination was used in $22 \%$ of cases. Median groin puncture to final recanalization time was $27 \mathrm{~min}$ and $\mathrm{mTICl} 2 \mathrm{~B} / 3$ recanalization was achieved in $94 \%$ of cases. There were 2 intra-procedural complications, neither related to the microcatheter. In all cases, the Headway27 reached the intended target vessel: M1 $(n=4), \mathrm{M} 2(n=26), \mathrm{M} 3$ $(n=13), \mathrm{P} 2(n=3), \mathrm{P} 3(n=1)$, and basilar artery $(n=3)$. There were no cases requiring usage of an additional or alternative microcatheter. In 45/47 cases of MAT, the reperfusion catheter tracked over the Headway to the clot/intended target; in two cases, the microcatheter was used to deploy a stentriever that then allowed the reperfusion catheter to track to the clot. Conclusion: The Headway27 microcatheter reliably facilitated rapid clot access in anterior and posterior circulation acute large vessel occlusions with no microcatheter-associated complications.




\section{Introduction}

Continued technological advancements in guide catheters, reperfusion catheters, and microcatheters have steadily made acute stroke interventions faster, safer, and more efficacious. Many of the recent technological developments have been focused on the two former components of the triaxial system without focus on the microcatheter [1-3]. The Headway27 (MicroVention, Inc., Aliso Viejo, CA, USA) is a 0.027 -inch microcatheter originally designed for the delivery of flow diverters; however, its use has not been described as a component of a stroke intervention system. Here we describe our experience with the Headway 27 microcatheter in 50 consecutive ischemic stroke interventions with particular focus on its ability to reach a vascular target, deliver an aspiration catheter to an occlusive clot, and to deliver a stentriever.

\section{Methods}

\section{Patient Selection and Data Collection}

We retrospectively reviewed a prospectively collected acute stroke thrombectomy database to identify 50 consecutive cases from April to July 2017 utilizing the Headway27 microcatheter as a component of a trior quadraxial thrombectomy access system. Data were collected with respect to patient demographics and clinical considerations, procedural equipment, and technical details.

Endovascular Procedure

In this series, access for acute stroke thrombectomies was achieved with one of two 8-Fr non-balloon guide catheters with or without the assistance of an 8-Fr 65-cm arrow sheath. A VTK catheter was used to select and advance the guide catheter into the appropriate cervical parent vessel. Via the guide catheter a reperfusion catheter was advanced over the Headway 27 microcatheter to engage the clot. As described previously, manual aspiration thrombectomy (MAT) utilizing a syringe was performed [4,5]. Our protocol involved two attempts of syringe-mediated MAT. In cases where MAT proved ineffective or where the primary neurointerventionalist felt that the efficacy of MAT would be limited by anatomic considerations, a stentriever was deployed via the Headway 27 microcatheter and the reperfusion catheter was advanced over the stentriever and aspiration was applied (stent-assisted manual aspiration thrombecomy [SMAT]) [6].

\section{Results}

\section{Background and Demographics}

Over a 3-month period, we performed 50 consecutive acute thrombectomies using the Headway 27 as our primary microcatheter. Average patient age in the series was 70 (SD 14) and 54\% were female. Mean NIHSS at the time of treatment was 16 (SD 7) and 32\% of patients received tPA prior to thrombectomy. Initial location of the occlusion was most commonly the M1 (27, 54\%). Other locations included the ICA terminus $(9,18 \%)$, M2 $(7,14 \%)$, basilar $(6$, $12 \%)$, and P1 (1, 2\%). A coexistent ipsilateral extracranial carotid occlusion was found in 10 cases $(20 \%)$.

\section{Thrombectomy Technique and Results}

MAT technique was used primarily in 47 patients (94\%) and required conversion to SMAT in 11 patients $(23 \%)$. In the 36 patients treated exclusively with MAT, the median number of passes was 2 , and $30 \%$ had successful recanalization after the first pass. SMAT technique was used primarily in 3 patients $(6 \%)$. The median groin puncture to clot access time was $16 \mathrm{~min}$ and the median groin puncture to final recanalization time was $27 \mathrm{~min}$. The rate of TICI $2 \mathrm{~b} / 3$ recanalization was $94 \%$. In comparing MAT alone and MAT with rescue 
SMAT, there was no significant difference in mean total procedural time (34 vs. $35 \mathrm{~min}$ ) or rate of TICI2b/3 recanalization (97 vs. 93\%). While two complications occurred in the series, neither was associated with the microcatheter. In one instance, a microwire perforated a distal M3 branch while attempting to aspirate distal emboli after clearance of a more proximal occlusion. Additionally, there was one episode of reperfusion catheter fracture necessitating snare recovery. Mean change in NIHSS score at $24 \mathrm{~h}$ was -6.7 (SD 7.6, median -6.5) and in patients with 3-month follow-up data available $(n=29), 48 \%$ had an mRS of $0-2$.

\section{Microcatheter Performance}

In all 50 cases, the Headway27 reached the intended target vessel: M1 $(n=4), \operatorname{M} 2(n=$ $26), \mathrm{M} 3(n=13), \mathrm{P} 2(n=3), \mathrm{P} 3(n=1)$, and basilar artery $(n=3)$. The microcatheter was used to deliver 8 different reperfusion catheters (0.044-0.072 inches ID range). In 45/47 MAT cases (96\%), the reperfusion catheter tracked over the Headway27 to the clot/intended target; in two cases, the Headway was used to deploy a stentriever that then allowed the reperfusion catheter to track to the clot. Both cases were in the context of needing to bring the reperfusion catheter around the carotid siphon into the ophthalmic segment.

There were no cases requiring usage of an additional Headway or alternative microcatheter for thrombectomy. Both the Solitaire $(n=9)$ and Trevo $(n=5)$ stentrievers were used without difficulty in deployment of either 4 or $6 \mathrm{~mm}$ sizes. There were no complications such as dissection or perforation related to the usage of the Headway microcatheter.

\section{Discussion}

With definitive randomized controlled trials demonstrating that acute stroke thrombectomy improves outcomes in patients with large vessel occlusions up to $24 \mathrm{~h}$ from onset of symptoms, much of the current lines of inquiry revolve around how we can perform the procedure faster, safer, and more effectively [7-10]. While current debates include reperfusion catheter selection, utility of stentrievers versus direct aspiration, and utility of aspiration pumps, there has been very little investigation in regard to the optimal microcatheter system to use to deploy stentrievers or deliver reperfusion catheters [4,11-14]. We would posit that the optimal microcatheter for acute ischemic stroke intervention would have the following characteristics: length sufficient to reach the distal vasculature without sacrifice of catheter flexibility, intrinsic trackability to negotiate distal cerebral vasculature but with enough stiffness to deliver a bulky reperfusion catheter, sufficient visibility for safe travel through the distal cerebral vasculature (particularly in the context of procedures performed under MAC), and ability to deploy a stentriever safely and efficiently.

While the Headway27 microcatheter (MicroVention Inc, Aliso Viejo, CA, USA) was originally designed for delivery of flow diverters, it has many of the characteristics that also make it a promising acute stroke intervention microcatheter. Distal purchase with guidewires and microcatheters is a previously described technique used to negotiate tortuous vasculature [15]. To this end, the Headway27, with its hybrid braid/coil construction and a distal large ID and relatively small OD (0.027 inches and $2.6 \mathrm{Fr}$, respectively), tracks easily into the distal cerebral vasculature and delivers various sized reperfusion catheters without difficulty. In this series, the Headway 27 was used to deliver 8 different reperfusion catheters that ranged in ID from 0.044 to 0.072 inches and only twice required supplementation with a stentriever due to inability to deliver the reperfusion catheter past the ophthalmic origin to the vascular target. While previous descriptions of avoidance of the ophthalmic "legde effect" have utilized larger profile microcatheters, the Headway 27 is capable of performing the same task with a smaller outer diameter making it safer in the distal vasculature [16]. Additionally, a 3.1-Fr 
Ares et al.: Headway27 for Stroke

Fig. 1. Visibility of microcatheters. The distal $5 \mathrm{~cm}$ of each catheter is visualized via fluoroscopic image. From top to bottom: Headway27 (MicroVention), Marksman (Medtronic), Velocity (Penumbra), and 3MAX (Penumbra).

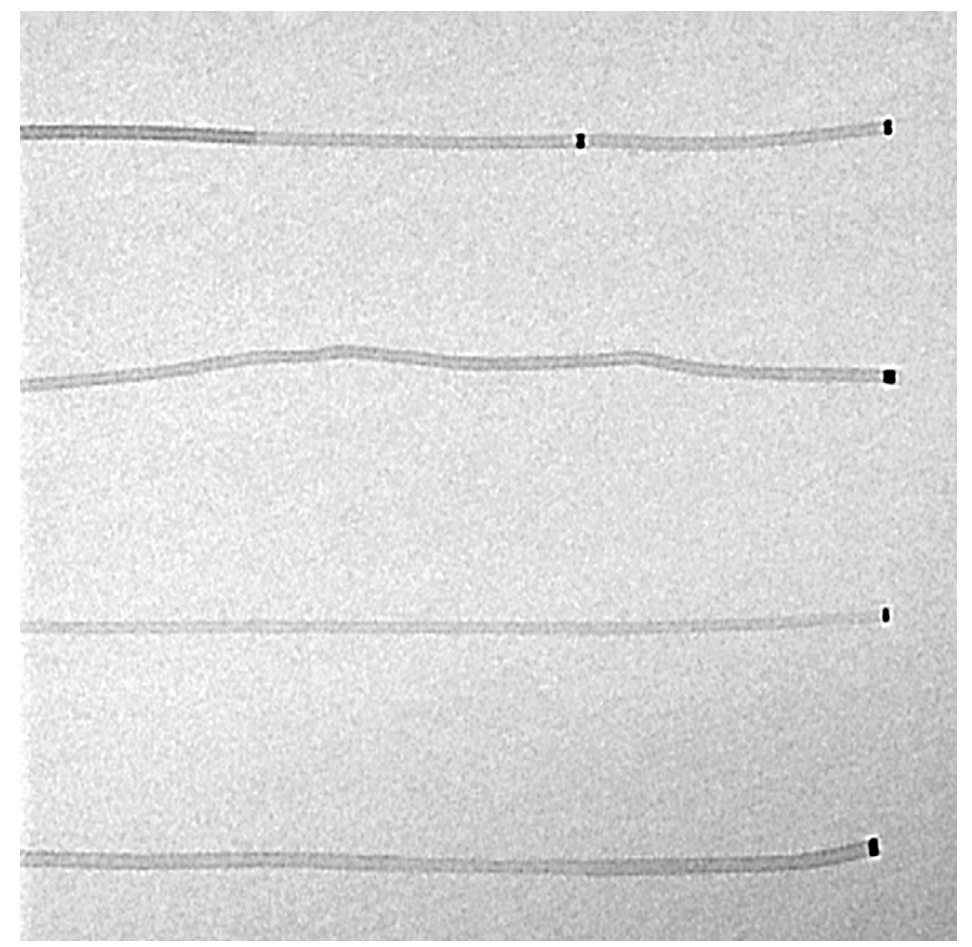

Table 1. Comparison of microcatheter characteristics

\begin{tabular}{lllll}
\hline Microcatheter & Proximal OD, Fr & Distal OD, Fr & Distal ID, in & Length, cm \\
\hline Headway27 & 3.1 & 2.6 & 0.027 & 156 \\
Marksman & 3.2 & 2.8 & 0.027 & 150,160 \\
Velocity & 2.9 & 2.6 & 0.025 & 160 \\
3MAX & 4.7 & 3.8 & 0.035 & 153 \\
Excelsior XT-27 & 2.9 & 2.7 & 0.027 & 150 \\
Phenom 27 & 3.0 & 2.7 & 0.027 & 150 \\
\hline
\end{tabular}

proximal OD and semi-rigid proximal section provides sufficient support for 1:1 pushability even in tortuous distal anatomy. We found that the Headway 27 was easily advanced as distal as the M3 without complication or need to exchange to another microcatheter to deploy a stentriever. Additionally, dual distal markers and a radiodense segment that extends nearly to the distal tip of the catheter make it exceptionally visible and improve the safety profile of a procedure that may be optimally done under mild i.v. conscious sedation (Fig. 1) [17].

In comparison to commonly used microcatheters, the Headway27 compares very favorably due to a number of factors (Table 1; Fig. 1). When compared to Velocity (Penumbra, Inc., Alameda, CA, USA), it is significantly more visible and has a larger ID for better angiographic runs and easier stent delivery. Headway27 also has a lower profile than the $3 \mathrm{MAX}$ (Penumbra, Inc., Alameda, CA, USA) catheter, making it more trackable with the added ability to deploy a stentriever. It has a smaller distal OD than Marksman (Medtronic, Minneapolis, MN, USA) without sacrificing distal ID, making it more flexible and more easily trackable with the same ability to perform angiographic runs. In comparison to the Excelsior XT-27 (Stryker, Fremont, CA, USA) and Phenom 27 (Medtronic, Minneapolis, MN, USA), Headway27 is longer and has a smaller distal OD, making it more suitable for safe delivery to more distal microvas- 
culature, an important characteristic when trying to advance an aspiration catheter around the carotid siphon to the clot target. Moreover, unlike the other commonly used stroke microcatheters, Headway is officially approved for usage of either NBCA or Onyx in cases of wire perforation of the distal vasculature.

While flexibility and visibility are relatively subjective measures that we feel favor the usage of the Headway 27 microcatheter for stroke thrombectomy, our clinical results and the fact that it was used to deliver a variety of aspiration catheters speaks to its safety and efficacy as a stroke microcatheter. As reinforced in the table, the dimensions of the catheter objectively compare quite favorably to alternative, comparable microcatheters, specifically in terms of microcatheter length and distal OD. As a more objective measure of utility, we feel that our $96 \%$ rate of successful delivery of the reperfusion catheter over the Headway to the intended target will serve as a useful benchmark for potential comparison to other microcatheters.

\section{Conclusion}

The Headway27 microcatheter can be used safely as a component of a triaxial acute stroke intervention system. Its dimensions and visibility compare very favorably to alternative microcatheters. In this series, it reliably and efficiently delivered reperfusion catheters and stentrievers to the distal cerebral vasculature without complication.

\section{Disclosure Statement}

No authors have any financial or consulting interests with MicroVention. B.T.J. is a consultant for Medtronic. T.G.J. is a consultant for Neuravi, Codman Neurovascular, Stryker (PI DAWN; unpaid), Fundacio Ictus (PI REVASCAT; unpaid), and holds stock in Anaconda, Silk Road, Blockade. This research received no specific grant from any funding agency in the public, commercial, or not-for-profit sectors.

\section{Author Contributions}

Drafting of the Article: W.J.A., B.A.G. Acquisition of data/data analysis: W.J.A., B.M.Z., C.L.K., G.M.W., H.Z., D.B. Reviewed and revised article prior to submission: all authors. Study supervision: B.A.G. Data sharing: N/A.

\section{References}

1 Mohlenbruch MA, Kabbasch C, Kowoll A, et al: Multicenter experience with the new SOFIA plus catheter as a primary local aspiration catheter for acute stroke thrombectomy. J Neurointerv Surg 2017;9:1223-1227.

$\longrightarrow 2$ Turk AS, Frei D, Fiorella D, et al: ADAPT FAST study: a direct aspiration first pass technique for acute stroke thrombectomy. J Neurointerv Surg 2014;6:260-264.

3 John S, Hussain MS, Toth G, et al: Initial experience using the 5MAX ACE reperfusion catheter in intra-arterial therapy for acute ischemic stroke. J Cerebrovasc Endovasc Neurosurg 2014;16:350-357.

-4 Gross BA, Jadhav AP, Jovin TG, et al: Dump the pump: manual aspiration thrombectomy (MAT) with a syringe is technically effective, expeditious, and cost-efficient. J Neurointerv Surg 2018;10:354-357.

5 Jankowitz B, Grandhi R, Horev A, et al: Primary manual aspiration thrombectomy (MAT) for acute ischemic stroke: safety, feasibility and outcomes in 112 consecutive patients. J Neurointerv Surg 2015;7:27-31.

-6 Jadhav AP, Aghaebrahim A, Horev A, et al: Stent retriever-mediated manual aspiration thrombectomy for acute ischemic stroke. Interv Neurol 2017;6:16-24.

7 Nogueira RG, Jadhav AP, Haussen DC, et al: Thrombectomy 6 to 24 Hours after Stroke with a Mismatch between Deficit and Infarct. N Engl J Med 2018;378:11-21. 


\section{Interventional Neurology}

8 Goyal M, Menon BK, van Zwam WH, et al: Endovascular thrombectomy after large-vessel ischaemic stroke: a meta-analysis of individual patient data from 5 randomised trials. Lancet 2016;387:1723-1731.

-9 Jovin TG, Chamorro A, Cobo E, et al: Thrombectomy within 8 hours after symptom onset in ischemic stroke. N Engl J Med 2015;372:2296-2306.

10 Jovin TG, Albers GW, Liebeskind DS: Stroke treatment academic industry roundtable: the next generation of endovascular trials. Stroke 2016;47:2656-2665.

11 Lapergue B, Blanc R, Gory B, et al: Effect of Endovascular Contact Aspiration vs Stent Retriever on Revascularization in Patients with Acute Ischemic Stroke and Large Vessel Occlusion: The ASTER Randomized Clinical Trial. JAMA 2017;318:443-452.

$\$ 12$ Turk AS, Turner R, Spiotta A, et al: Comparison of endovascular treatment approaches for acute ischemic stroke: cost effectiveness, technical success, and clinical outcomes. J Neurointerv Surg 2015;7:666-670.

13 Phan K, Dmytriw AA, Teng I, et al: A Direct Aspiration First Pass Technique vs Standard Endovascular Therapy for Acute Stroke: A Systematic Review and Meta-Analysis. Neurosurgery 2017, DOI: 10.1093/neuros/nyx386.

14 Lapergue B, Blanc R, Gory B, et al: Effect of endovascular contact aspiration vs stent retriever on revascularization in patients with acute ischemic stroke and large vessel occlusion. JAMA 2017;318:443-452.

15 Lee TH, Choi CH, Park KP, Sung SM, Lee SW, Lee BH, Kim DH, Kim HJ, Kim CW, Kim S: Techniques for intracranial stent navigation in patients with tortuous vessels. Am J Neuroradiol 2005;26:1375-1380.

16 Yoo AJ, Frei D, Tateshima S, et al: The Penumbra Stroke System: a technical review. J Neurointerv Surg 2012; 4:199-205.

17 Brinjikji W, Pasternak J, Murad MH, et al: Anesthesia-Related Outcomes for Endovascular Stroke Revascularization: A Systematic Review and Meta-Analysis. Stroke 2017;48:2784-2791. 